\title{
Commentary: Through thick and thin
}

\author{
Tain-Yen Hsia, MD, MSc, ${ }^{a}$ and Richard Figliola, $\mathrm{PhD}^{\mathrm{b}}$
}

\author{
From the a Department of Pediatric Cardiac Surgery, Yale New Haven Children's Hospital, Yale School of Med- \\ icine, New Haven, Conn; and ${ }^{\mathrm{b}}$ Department of Mechanical Engineering, Clemson University, Clemson, SC. \\ Disclosures: Authors have nothing to disclose with regard to commercial support. \\ Received for publication April 11, 2019; accepted for publication April 11, 2019; available ahead of print May 27, \\ 2019. \\ Address for reprints: Tain-Yen Hsia, MD, MSc, Pediatric Cardiac Surgery, Yale School of Medicine, 333 Cedar St, \\ PO Box 208064, New Haven, CT 06520-8064 (E-mail: tain-yen.hsia@yale.edu). \\ J Thorac Cardiovasc Surg 2019;158:e117-8 \\ $0022-5223 / \$ 36.00$ \\ Copyright (C) 2019 by The American Association for Thoracic Surgery \\ https://doi.org/10.1016/j.jtcvs.2019.04.046
}

By all accounts, Jean Léonard Marie Poiseuille (Figure 1) was a man of mystery. Despite his numerous contributions to mathematics, physics, engineering, and medicine, very little is actually known about his life. ${ }^{1}$ Born in Paris in 1799 to a carpenter, he entered the elite École Polytechnique at the age of 18, but left when the school was closed by Louis XVIII during the Second Bourbon Restoration. He switched to study medicine instead, and became a doctor of science in 1828 with his dissertation, "Recherches sur la Force du Coeur Aortique [Research on the Force of the Aortic Heart].", It is not clear whether he ever practiced medicine, as there were no recorded official positions for Poiseuille until 1860, when he resurfaced as an inspector of public school sanitation in the Seine district. Nonetheless, it is believed that his months at École Polytechnique contributed to his extraordinary sense of experimental precision, which culminated in the derivation of the mathematical principles governing fluid flow through a pipe, an equation that bears his name. It was during his efforts to set out a functional relationship of flow, pressure drop, tube length, and tube diameter that Poiseuille observed that the use of mercury instead of water as the fluid medium resulted in different results. By introducing the term viscosity, Poiseuille not only proved Newton's supposition that viscosity impacted fluid motion to be correct but also established a scientific method to measure fluid viscosity. ${ }^{*}$ To honor his discovery, viscosity is measured today in the metric system in units called poise or poiseuille.

In their Brief Research Report in this issue of the Journal, Schäfer and colleagues ${ }^{3}$ describe a focused 4-dimensional magnetic resonance imaging study of the aortic flow dynamics in 4 patients with hypoplastic left heart syndrome (HLHS). By quantifying viscous energy losses, they show that in 2 sets of patients ( 2 with superior cavopulmonary circulation and 2 with total cavopulmonary circulation), flow inefficiencies can be attributed to the exaggerated size and

\footnotetext{
* Although Sir Isaac Newton is credited with being the first to describe the mathematical equation for viscosity, Poiseulle is the first to accurately describe and measure viscosity.
}

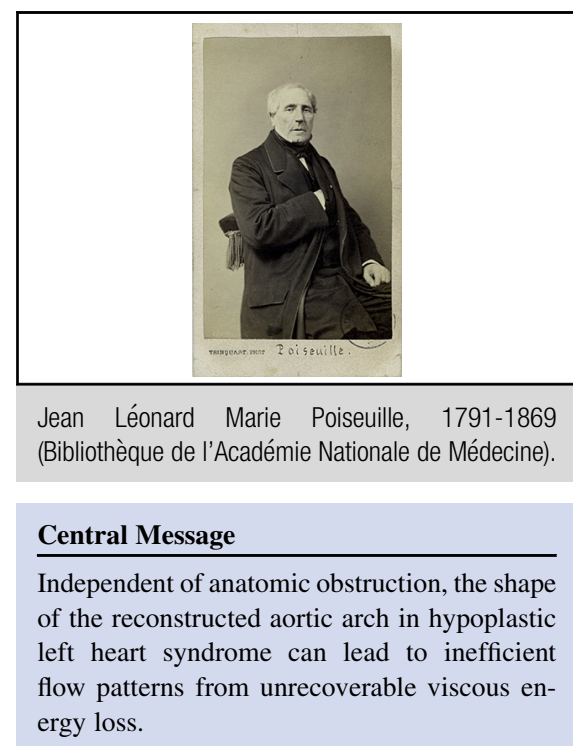

See Article page e113. pendent of clinically important residual stenosis or coarctation. To understand what this means, a little background is needed. Mechanical energy can be described as the ability to move the mass of an object over some distance, such as occurs in blood flow. According to Newton's laws, the total energy of a closed system is always conserved. This energy, however, may go from macroscopic motion (fluid flow) into random vibrations of the molecules. In the case of idealized flow, in which no frictional forces are present, the flow of a nonviscous (inviscid) fluid, this means that any increase in potential energy (pressure) will be compensated by a decrease in kinetic energy (velocity), and vice versa. Blood is viscous, ${ }^{\dagger}$ however, and its motion can produce friction and shear that will partially convert kinetic and potential energies into acoustic and thermal energies. These viscosityrelated energy transfers represent permanent, unrecoverable losses to the usable mechanical energy of the system. One can think of a murmur as a type of viscous energy loss that is caused by turbulence and friction. Another way to think about viscous energy loss is by blowing honey (vs water) through a small straw until one's face is red.

So, why is this preliminary study of 4 patients important? It is because recent efforts with advanced imaging and statistical shape analysis have revealed the importance of

\footnotetext{
${ }^{\dagger}$ We often incorrectly measure blood viscosity clinically by hematocrit. Erythrocyte content is only one of several variables affecting blood viscosity, with others being temperature, plasma fibrinogen, platelets, and structure and amount of proteins.
} \section{.}




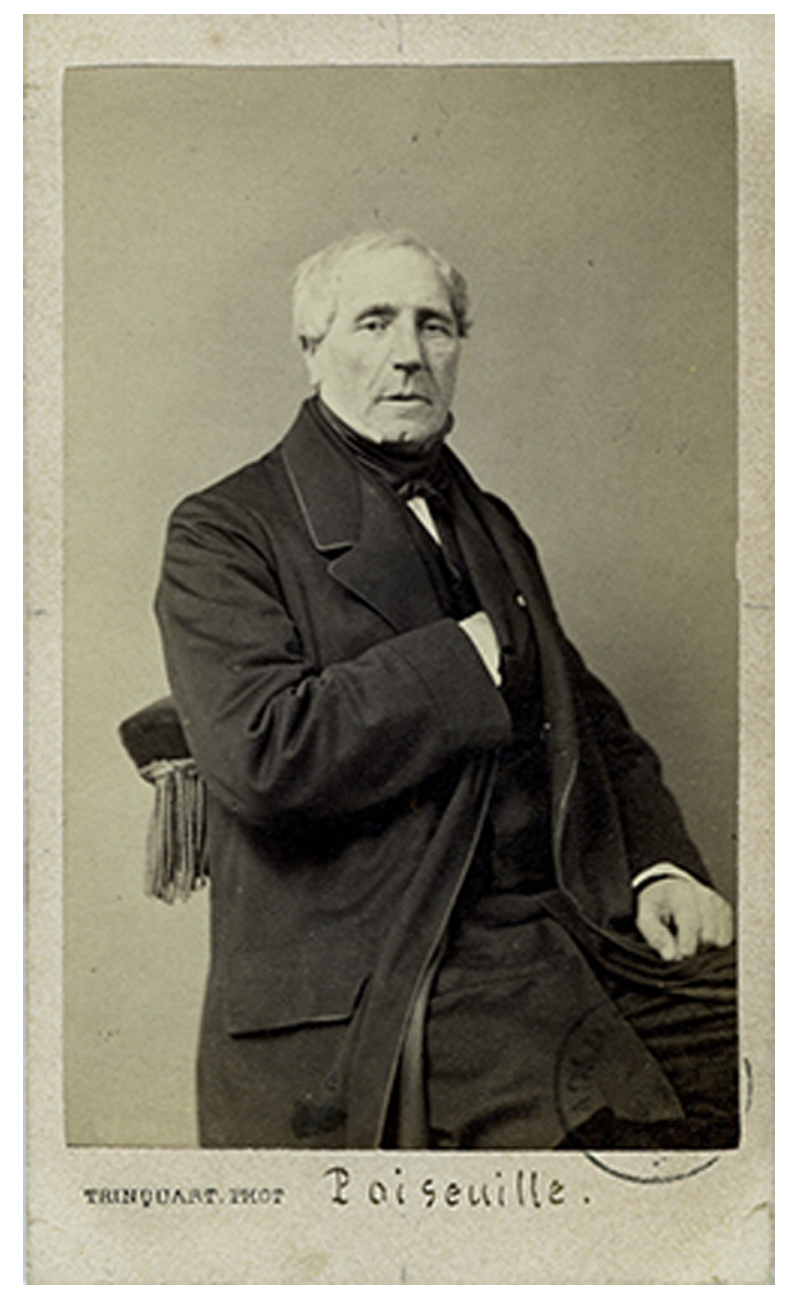

FIGURE 1. Jean Léonard Marie Poiseuille (1791-1869). Reprinted with permission from Bibliothèque de l'Académie Nationale de Médecine (Paris, France).

aortic shape, independent of anatomic obstruction, in clinical outcomes both in patients with HLHS and in patients after isolated aortic coarctation repair. ${ }^{4,5}$ Although revealing, those studies were unable to provide a mechanistic explanation for the observed relationship between shape and outcomes, such as late ventricular performance. This investigation by Schäfer and colleagues $^{3}$ with 4-dimensional magnetic resonance imaging provides an early insight into how shape alone can impact flow and function. Although only 4 patients were enrolled in this focused examination, the differences in flow characteristics, and possibly efficiency, are clear. This study is therefore a welcome, if preliminary, answer to the "how" question left from the previous shape analysis investigations. Certainly, the light shed by this study can be the basis for a larger study enrolling more patients to uncover possible correlations between viscous energy loss and clinically relevant parameters and outcomes.

Although Poiseuille's name is permanently associated with the physiology of blood flow through the artery, mysteries remain as to where he did his work and how it was financially supported. It has been pointed out that during his lifetime, Poiseuille was only modestly recognized; he was forever refused admission to the prestigious Academy of Sciences and only received 700 francs in research prizes in medicine and surgery. His precision instruments must have been costly, however, and the elaborate experimental apparatus required expert glass blowers. Poiseuille was of course credited with inventing the U-tube mercury manometer to measure blood pressures accurately, and to this day blood pressures are reported in millimeters of mercury $(\mathrm{mm} \mathrm{Hg})$. One has to wonder how we would be reporting blood pressures today if he had used honey, instead of mercury, to save some money back in 1828 . How about mm Hy?

\section{References}

1. Sutera SP. The history of Poiseuille's law. Annu Rev Fluid Mech. 1993;25:1-19.

2. Poiseuille JL. Recherches sur la force du coeur aortique. Paris: Didot le Jeune; 1828. Available at: https://archive.org/details/b22291611.

3. Schäfer M, DiMaria MV, Jaggers J, Mitchell MB. Suboptimal neoaortic arch geometry correlates with inefficient flow patterns in hypoplastic left heart syndrome. J Thorac Cardiovasc Surg. 2019;158:e113-6.

4. Bruse JL, Cervi E, McLeod K, Biglino G, Sermesant M, Pennec X, et al; Modeling of Congenital Hearts Alliance (MOCHA) Collaborative Group. Looks do matter! Aortic arch shape after hypoplastic left heart syndrome palliation correlates with cavopulmonary outcomes. Ann Thorac Surg. 2017;103:645-54.

5. Bruse JL, Khushnood A, McLeod K, Biglino G, Sermesant M, Pennec X, et al; Modeling of Congenital Hearts Alliance Collaborative Group. How successful is successful? Aortic arch shape after successful aortic coarctation repair correlates with left ventricular function. J Thorac Cardiovasc Surg. 2017;153: 418-27. 